\title{
O Brasil e a não-indiferença à crise haitiana: solidariedade ou retórica do discurso?*
}

\author{
Amanda Sanches Daltro de Carvalho ${ }^{1}$ \\ Renata de Melo Rosa ${ }^{2}$
}

\section{Resumo}

O Brasil, após a queda do muro de Berlim, tem centrado esforços para desenvolver uma política de prestígio que se contraponha à política neoliberal do Norte. Não obstante, o país tem buscado firmar liderança na sua região, além de ter definido em sua agenda externa a aproximação, sustentada no diálogo e na cooperação, com os países árabes, latino-americanos e africanos. Ademais, tem pleiteado incisivamente a reforma do Conselho de Segurança da ONU, argumentando que esse espaço deve corresponder a uma nova ordem que implica na participação mais ativa dos países em desenvolvimento, não se eximindo também de eliminar as desigualdades entre estes e os países industrializados. Dessa forma, o Brasil projeta-se como um mediador nas relações Norte-Sul, buscando sempre afirmar a soberania das nações. Em abril de 2004, aceitou liderar a Missão das Nações Unidas para a Estabilização do Haiti (Minustah), oportunidade que tem permitido ao país aplicar a sua política pacifista e de mediação. Nesse sentido, adotando a Minustah como estudo de caso, o presente artigo tem por objetivo analisar se a atuação brasileira frente a essa operação de paz condiz com seu discurso de não ingerência e não indiferença e, por fim, levantar questões que podem decorrer dessa atuação.

Palavras-chave: Brasil. Haiti. Minustah. Conselho de Segurança da ONU.

Recebido em 09.03.2011.

Aprovado em 25.04.2011.

1 Doutoranda em Política Internacional e Resoluções de Conflitos, do Centro de Estudos Sociais-CES e do Departamento de Economia, da Universidade de Coimbra. Email: amanda.sanches2@gmail.com.

2 Pós-Doutorado em Relações Internacionais; Coordenadora do curso de Relações Internacionais do UniCEUB; Líder do Núcleo de Estudos de Diplomacia Responsável. Email: renata.rosa@uniceub.br. 


\section{Introdução}

A configuração de uma nova ordem mundial após a queda do muro de Berlim vem acompanhada de novos desafios. Consoante à esfera da segurança internacional, conflitos intraestatais têm-se tornado um ponto central na discussão dos formuladores de política. Com efeito, comunidade internacional e acadêmicos da área ocupam-se em debater e estudar os mecanismos que melhor se aplicam na resolução bem-sucedida e sustentável dos litígios (CHANDLER, 2006; PARIS, 2004; BREWER, 2010; RICHMOND, 2008).

Por outro lado, Chefes de Estado de países em desenvolvimento clamam pela constituição de uma nova ordem mundial mais democrática e justa e atribuem ao modelo vigente a responsabilidade pelos problemas latentes (BRASIL, 2010a; ESTADÃO, 2010). Nesse sentido, apresentam-se como movimentos de resistência, somados também às organizações não governamentais, porquanto produzem práticas locais que tendem a se distanciar dos modelos político e econômico globais.

Por conseguinte, países emergentes que se limitavam a estabelecer acordos com os Estados Unidos e União Europeia, têm destinado esforços para o estreitamento das relações entre si, com objetivo de constituir novos espaços que contemplem a representação democrática e fomentem a construção de novas políticas voltadas para o desenvolvimento.

Nesse contexto em que se questiona a configuração da ordem vigente e seus efeitos, sobretudo nos países menos avançados, o Brasil tem ressaltado constantemente que a construção da paz sustentável não pode prescindir da implementação efetiva da justiça social, suportada pelo desenvolvimento desses países (HURRELL, 2010), pela atenção aos direitos humanos (princípio consagrado constitucionalmente por sua Constituição Federal) e, no cenário internacional, pela participação democrática e multilateral dos Estados.

Dessa forma, o direcionamento da política externa brasileira volta-se solidariamente aos países mais necessitados, ao tempo em que fortalece as relações com os países vizinhos, africanos e árabes. À medida que se contrapõe às políticas adotadas pelos Estados Unidos, sobretudo, a partir da sua política unilateral e 
agenda de segurança internacional contra o terrorismo (BRASIL, 2010a), o Brasil aproxima-se da América do Sul e demais países emergentes (HURRELL, 2010).

No campo dos conflitos internacionais, o país que consagra em sua Constituição o direito de não intervenção (BRASIL, 1988) tem apostado no processo mediático como o melhor caminho para resolver as contendas. Entretanto, em observância à solidariedade aos demais Estados, o país tem-se valido do princípio da não indiferença ao considerar que não pode declinar de prestar assistência aos países necessitados.

Sustentado por este último princípio e em atenção aos problemas dos vizinhos regionais, o Brasil aceitou, em 2004, exercer o comando da Missão de Estabilização das Nações Unidas para o Haiti (Minustah), objetivando imprimir uma nova forma de atuação, contrária à que vinha sendo aplicada pelos Estados Unidos e Canadá no Haiti. Entretanto, avaliando a atuação brasileira frente ao processo de elaboração do mandato da Missão e em campo, os resultados não são satisfatórios se adotarmos o discurso do país e os princípios que regem sua política externa.

Nesse sentido, para melhor compreensão da análise que se propõe, o presente artigo divide-se em três partes. Na primeira seção, demonstra-se a dinâmica que se observa em torno da relação Norte-Sul, contra a qual emergem discussões e questionamentos, situação que propicia práticas alternativas e o surgimento de novos atores. Na seção seguinte, apresenta-se a atuação brasileira face à ordem mundial vigente, sustentando a necessidade de se promoverem mudanças que reflitam a nova realidade.

Não obstante a afirmação do país como um ator indispensável à Comunidade Internacional, argumenta-se que essa projeção é concretizada pela sua política de prestígio, nos termos propostos por Morgenthau (1993). Na terceira seção, o artigo analisa se a inserção brasileira no cenário internacional a partir do seu discurso e comportamento, enquadrados como política de prestígio, é corroborada pela sua atuação na elaboração da resolução que deu origem à Minustah e à frente do Force Commander, adotando como referencial os princípios da não ingerência e da não indiferença. Por derradeiro, conclui-se o artigo afirmando que o Brasil, dese- 
jando firmar-se como um importante ator na esfera internacional, tomou decisões contraditórias frente à MINUSTAH, que podem impedir a concretização de outros projetos e levantar questionamentos sobre a solidez da sua política de prestígio.

\section{A Ordem Mundial}

Durante a LII Assembleia Geral das Nações Unidas (AGNU), em 1998, o Brasil apresentou sua posição acerca da reforma do Conselho de Segurança (CS). Foi incisivo ao defender uma reforma que abrangesse o aumento do número de assentos permanentes e não permanentes do CS, resguardando a representação de ambos os países industrializados e em desenvolvimento, de forma a garantir a redução da discriminação fixada na relação Norte-Sul e refletir a um novo arranjo internacional (CORRÊA, 2007). No mesmo sentido, defendeu que a utilização do veto deve ser limitada a algumas circunstâncias, mas, entretanto, a ONU deve caminhar no sentido de eliminá-lo da sua estrutura e qualquer reforma que não observe essas considerações não pode ser aceitável, sobretudo quando se reafirma a desigualdade entre os países e fere os princípios democráticos (CORRÊA, 2007).

A construção desse discurso, que visa à ruptura com os estereótipos sacramentados em torno da relação Norte-Sul, fundamenta-se no entendimento de que os países do Terceiro Mundo associam-se à pobreza, à exclusão, ao subdesenvolvimento e aos conflitos internos, em contraste à solidez dos países de Primeiro Mundo (WOODWARD, 2006). Reconhecendo os efeitos que essa abordagem imprime nos países em desenvolvimento, o Brasil e outros atores governamentais têm se dedicado a alertar a Comunidade Internacional que esses países também podem contribuir com práticas diversas das implementadas, motivadas pela solidariedade e pelo engajamento coletivo (SLATER, 2004).

Slater (2004) alerta que esse movimento protagonizado não apenas pelo Brasil, mas por outros países do Sul, pode assinalar uma nova possibilidade de counter-geopolitic, em referência à ordem configurada pela globalização e política neoliberal, promovida pelo Norte, visto que propõe uma ordem alternativa de organização do mundo. O Fórum Social Mundial inaugurado em Porto Alegre 
é um exemplo, segundo o autor, de tentativa de propor um novo caminho para as políticas, pautado na promoção da dignidade da pessoa, na busca de uma democracia mais sólida e participativa e da justiça social. Com efeito, as organizações não governamentais e governamentais e indivíduos participantes do evento expressam-se contrários às práticas imperialistas e de modelos que tenham por objetivo colonizar.

Esses espaços que fomentam a produção de mecanismos alternativos aos vigentes e transformam-se em locais de resistência surgem em consequência da nova ordem mundial, sacramentada com o fim da Guerra Fria. Na atualidade, a política de segurança, antes centrada no eixo Leste-Oeste, volta-se para o eixo Norte-Sul, sendo este último a sede de frágeis democracias que permitem a atuação de grupos paralelos, o abrigo de terroristas, a rota do tráfico de drogas, entre outros (WOODWARD, 2006; PARIS, 2004).

Nesse cenário de ações direcionadas aos países do sul, de imposição de modelos de governança e de políticas econômicas, por muitos classificados como neocolonialismo, surgem movimentos de resistência a essa nova ordem mundial (PECEQUILO, 2005), além de serem projetados países em desenvolvimento como protagonistas, a exemplo do Brasil (HURRELL, 2010).

\section{Brasil e a política de prestígio}

Durante visita realizada à cidade de Doha, Catar, em maio de 2010, em continuidade às negociações sobre a liberalização do comércio mundial, o presidente brasileiro, Luiz Inácio Lula da Silva, concedeu uma entrevista exclusiva à rede de televisão Al Jazeera. Interpelado a respeito de como se sentia diante do entusiasmo e dos aplausos de vários líderes mundiais e de sua eleição como o homem mais influente do mundo, pela revista Time, Lula respondeu:

[...] eu acho que nós estamos colhendo o resultado de um trabalho sério que nós estamos fazendo. Quando, no dia 10 de dezembro de 2002 - eu já estava eleito Presidente da República -, eu fui à Casa Branca conversar com o presidente Bush, e ele estava obsessivo com a Guerra do Iraque. Eu disse 
ao Presidente Bush: a minha preocupação, Presidente, não é o Iraque. A minha preocupação é a fome do meu povo. Eu tenho mais de 50 milhões de pessoas vivendo abaixo da linha da pobreza. Como é que eu vou me preocupar com o Iraque? Bem, o dado concreto é que hoje, passados sete anos, nós elevamos 31 milhões de brasileiros à classe média e tiramos 24 milhões de brasileiros da extrema pobreza. Essa é uma coisa muito importante para mim, me deixa muito feliz, e eu acho que há o reconhecimento do mundo, porque nós vamos cumprir todas as Metas do Milênio bem antes do prazo. Qual é a coisa importante? É que eu não sou um homem de ficar procurando encrenca, eu não gosto de encrenca. Eu quero gastar a minha energia tentando pensar numa coisa positiva, tentando pensar em ajudar alguém, tentando construir a paz. Não é possível você governar procurando inimigo, querendo uma guerra. (BRASIL, 2010b).

O trecho da entrevista concedida pelo Presidente é apenas uma ilustração dos princípios norteadores da política externa brasileira, fundados, entre outros, no diálogo, na solidariedade e na mediação. Em contraste à geopolítica do intervencionismo norte-americano, consubstanciada na expansão territorial, econômica e na subjugação dos povos (SLATER, 2004), o Brasil tem-se projetado como uma nação pacifista e como contrarrepresentação às políticas neoliberais. Mas esse movimento de resistência não se respalda apenas no Brasil, mas também nos demais países latino-americanos, sobretudo, na Venezuela e nos países da África, considerados também países emergentes.

Nessa conjuntura, o Brasil imprime um papel importante à medida que se projeta e lança à Comunidade Internacional as reivindicações dos países em desenvolvimento e chama atenção ás políticas que devem ser empregadas para construir uma paz sustentável. Nessa cruzada, sustentada não apenas pelo seu discurso desenvolvimentista (HURRELL, 2010), mas também pelo seu gigantismo em termos territorial, populacional e econômico, o Brasil coloca-se como um importante jogador na arena internacional, respaldado pelo seu soft power (LIMA; HISRT, 2006; HURRELL, 2010, BARBOSA et al, 2009).

A política humanista anunciada por Lula no ato da sua posse, em 2003, visa redesenhar a ordem mundial expressa no unilateralismo norte-americano, na assimetria entre os Estados e nas barreiras tarifárias impostas aos produtos dos países 
subdesenvolvidos (MIYAMOTO, 2000; PECEQUILLO, 2005). Em contrapartida, o presidente brasileiro proclamou o estreitamento das relações com os países da América Latina e da África, por exemplo, fora do eixo Estados Unidos - União Europeia (BRASIL, 2003). Não obstante, no plano doméstico, assim como na esfera internacional, tem buscado concretizar uma agenda social, ao passo em que almeja eliminar as desigualdades por meio da distribuição de renda e erradicar a fome, sobretudo, efetivando o programa Fome Zero (LIMA; HISRT, 2006).

No que concerne ao multilateralismo pregado pelo Brasil, muito se tem trabalhado na atuação política em vários Fóruns como o IBAS e o G20. A proposta é construir e fortalecer o diálogo entre os países que integram esses grupos, à medida que desenham políticas acordadas por todos, considerando que se apoiam mutuamente em torno de questões que implicam no reconhecimento de uma nova ordem, como a reforma do CS.

Nesse sentido, a opção por medidas mediáticas em contraposição ao uso de força militar reflete no atual argumento brasileiro que entende combater as ameaças externas focando no desenvolvimento, na economia (LIMA; HIRST, 2006). Ainda assim, em contributo à garantia da paz e da segurança internacionais, o Brasil não se exime de afirmar que esse objetivo só poderá ser alcançado quando a prioridade dos países, que promovem esse eixo, centre esforços no desenvolvimento econômico sustentável desses locais.

Em outras palavras, o que tem sido questionado pelo Brasil é a distribuição do poder em âmbito internacional, a política de segurança ditada pelos Estados Unidos e o tratamento dispensado aos Estados menos avançados. A proposta é uma agenda social pautada no desenvolvimento sustentável, na abertura e na flexibilização dos mercados, no multilateralismo, na integração internacional e na prática democrática mais justa e equitativa entre os atores (VAZ, 2009; MIYAMOTO, 1992; SPEKTOR, 2010, p. 35; HURRELL, 2010) e, sobretudo, na atenção à soberania dos Estados.

No que concerne à segurança internacional, dispensa-se as intervenções humanitárias, ações militares unilaterais e a proliferação de armas, sustentando a 
linha adotada da resolução pacífica dos conflitos, como tentou desempenhar nas tensões entre Venezuela e vizinhos, Bolívia e Equador (SARAIVA, 2007). Dessa forma, como argumentam Lima e Hisrt (2008, p. 38):

The Brazilian military budget is today relatively smaller than that of other South American countries such as Venezuela, Colombia and Chile, and its defence capability are far inferior to those of other intermediate power such as India, Egypt or Indonesia.

Ademais, o Brasil é signatário do Tratado de Não Proliferação Nuclear (TNP) e, portanto, sua atuação tem se concretizado em outras formas (MIYAMOTO, 2000).

Apoiando-se em tais ideia, vê-se que a política desenvolvida pelo Brasil volta-se fundamentalmente, para o prestígio. Como Morgenthau (1993) assegurou em sua obra Politics among nations, a política de prestígio insere-se como um terceiro elemento de luta pelo poder no cenário internacional, somada à política de imperialismo e a de status quo, mas diferencia-se destas, à medida que se dissocia do uso da força e da ameaça e busca o reconhecimento social.

Nessa perspectiva, por exemplo, em 1930, o presidente Franklin Roosevelt iniciou a sua política que ficou cunhada como "Good Neighbour Policy”, objetivando dar uma nova roupagem às agressivas ações de segurança dispensadas à América Latina. Essa decisão decorreu em observância aos movimentos de nacionalismo e resistência resultantes dessas ações, os quais poderiam impedir a plena execução desta política (SLATER, 2004).

Esse fato demonstra com precisão o que se objetiva alcançar com a política de prestígio: a aplicação de mecanismos que visem ao reconhecimento, pelos demais atores internacionais, do poder intrínseco de determinada nação. Esse prestígio poderia estar relacionado aos recursos militares, mas atualmente não se busca mais, ou, ao menos, não se justifica apenas o uso da força como mecanismo de afirmação no cenário internacional. Em contraposição, busca-se alcançar o prestígio dispondo-se de outros elementos, como a diplomacia, em alternativa à imposição da força. Nesse sentido, o Brasil abre espaço e ganha confiança, quando 
se propõe, por exemplo, a abandonar políticas pautadas no militarismo e no liberalismo, e fixar em sua política externa e interna uma agenda social e mediática (SARAIVA, 2007).

A atuação brasileira sustentada por esses valores pode parecer utópica. No entanto, ainda que o seja, reflete o anseio dos povos que clamam pelo fim dos conflitos e pela paz ou por respostas mais sustentáveis, efetivas e menos danosas em torno das ameaças, considerando também, como aponta Lafer (2000, p. 264), que o mundo está "permeado por descontinuidades e com um forte déficit de governabilidade".

Nesse sentido, a política de prestígio, que tem sustentado os alicerces da política externa brasileira, é valorizada em contextos que se exigem mudanças. Com efeito, a maximização de poder que emana dessa estratégia também vem acompanhada da responsabilização da sua utilização. É o que Morgenthau (1993) cunhou de corrupção da política de prestígio.

No caso do Brasil, essa ressalva também se aplica. O poder que vem adquirindo com a política de prestígio levanta questionamentos sobre: 1) a capacidade do país em cumprir e dar continuidade ao discurso e princípios que têm sustentado essa política e, consequentemente, 2) a capacidade de suportar os benefícios que dela podem decorrer, como a liderança da América do Sul e um assento no Conselho de Segurança. No primeiro caso, o poder adquirido é utilizado para sustentar o discurso que o concedeu ou, no sentido inverso, acaba por se corromper?

Na próxima seção, o presente artigo volta-se para a análise do primeiro tópico avaliando se o Brasil frente à Minustah mantém uma postura alinhada com o discurso que sustenta a sua política de prestígio.

\section{Dos bastidores à pratica: o Brasil na Minustah}

O Brasil emerge no cenário internacional como um aliado dos países emergentes em busca de mais espaço. Seu discurso pautado em multilateralismo, de- 
senvolvimento, justiça social, mediação, entre outros, como tratado acima, tem garantido ao país a aquisição de credibilidade, poder e, consequentemente, capital para barganha.

Aproveitando-se do seu prestígio perante a comunidade internacional, o Brasil esteve diretamente ligado nas discussões acerca da crise haitiana que vem se perpetrando há muitas décadas. Na sede da ONU ocupava, entre outras tarefas, a de discutir uma missão robusta para o país. Entretanto, em meio às negociações o Brasil mostrou-se contraditório em dois sentidos: quando aceitou liderar a missão pautada no uso da força, capítulo VII da ONU, e quando afastou da sua conduta o princípio da não interferência e também quando se intrometeu nos assuntos internos haitianos, a exemplo do apoio conferido à controvertida contagem de votos na eleição de René Préval (ROSA, 2008).

Em fevereiro de 2004, quando o presidente haitiano Jean-Bertrand Aristide deixou o país, o CS acompanhando os fatos, aprovou imediatamente uma missão para embarcar na ilha caribenha (ONU, 2004). A Resolução 1529 (MIF - Força Interina Multinacional) autorizava por até três meses a atuação de forças norte-americanas, canadenses, chilenas e francesas no país para conter a escalada da violência e preparar o terreno para a atuação de agentes externos e de uma nova missão (ONU, 2004).

Nesse processo, o Brasil apresentou a primeira falha. Votou a favor da MIF aprovada sob a égide do capítulo VII, mas, no entanto, recusou-se a contribuir com tropas, alegando que a Missão era sustentada pelo capítulo VII. Mais à frente, durante as negociações para a elaboração de um mandato robusto que contivesse eixos para promover o desenvolvimento do país, o Brasil apresentou outra contradição. Não só aprovou a nova Missão sustentada no capítulo VII, que ora se discutia, como também aceitou liderá-la em seu núcleo duro e realista, fazendo de sua contribuição principal o envio de soldados do exército (UZIEL, 2010; VEREINTACH, 2008).

Envolvido pelas críticas ante as contradições (CMI, 2004), o Brasil justificou-se alegando que não poderia deixar de contribuir com um país da região. $\mathrm{O}$ 
subterfúgio que justificou a sua atuação baseada no uso da força (capítulo VII) foi a evocação do princípio da não indiferença em detrimento ao princípio não ingerência.

Isso se observa porque, conjugado ao discurso emancipatório brasileiro, o princípio da não ingerência é uma cláusula constitucional constante e máxima que norteia a ação da política externa do Brasil (CF, 1988). Com efeito, consubstanciado nesse princípio, o país declinava da participação de missões, por exemplo, de intervenções humanitárias, uma vez que interferir em assuntos internos de outros países significa abrir precedente nesse campo e, consequentemente, estar disposto a suportar tais medidas em seu domínio doméstico; e, no mesmo sentido, reafirmando a sua posição pacifista e mediadora, recusava-se a integrar missões autorizadas sob o capítulo VII da Carta da ONU.

No entanto, dado esse novo contexto de afirmação na esfera internacional, por pressuposto, a utilização exclusiva do princípio da não ingerência poderia acarretar no engessamento da prática política brasileira e da defesa dos seus interesses. Como alternativa e abrandamento desse quadro, no entanto, tem-se evocado o princípio da não indiferença em alusão ao dever dos Estados perante os seus pares necessitados.

No contexto exposto na seção anterior, em que o Brasil tem-se projetado como uma potência regional em decorrência de seus atributos geográficos e econômicos e, sobretudo, da sua diplomacia solidária e conciliatória, a possibilidade de agir nos seus vizinhos não está descartada. Como aponta Celso Amorim (2005), à época Ministro das Relações Exteriores, em discurso proferido na XXXV Assembleia Geral da Organização dos Estados Americanos:

Alguns países da região têm experimentado dificuldades recorrentes em função, sobretudo, dos graves problemas econômicos e sociais, que ainda persistem em nosso continente. Diante de tais situações, é preciso estimular o diálogo entre os diferentes setores sociais, valorizar e fortalecer as instituições e apoiar soluções que podem e devem ser encontradas no plano nacional. A diplomacia brasileira pauta-se pelo princípio da não-ingerência em assuntos internos, consagrado em nossa Carta. O Governo do Presidente Lula tem associado a esse 
princípio básico uma atitude que descrevemos como de "nãoindiferença”. Temos prestado nosso apoio e solidariedade ativos em situações de crise, sempre que somos solicitados e consideramos ter um papel positivo.

De acordo com o então Ministro Celso Amorim, o princípio da não indiferença vem realçar o princípio da solidariedade e da justiça social que devem nortear a ação de qualquer Estado aos seus pares. Entretanto, esse subterfúgio utilizado pela diplomacia brasileira, conduz ao entendimento de que esse termo legitima o direito de ingerência, mas sob o auspício de outra linha diretora: a justiça social (LIMA, 2005). Dessa forma, essa atuação parece escamotear outros interesses que sustentam determinada ação, correspondendo o conceito de não indiferença a um mecanismo encontrado para justificá-la.

Esse exemplo demonstra o descompromisso brasileiro ante a linearidade das suas tomadas de decisão. No que concerne à Minustah, nota-se que o óbice não recai sobre o uso da força (Capítulo VII), mas em quando e como utilizá-la. Se o uso da força fosse a real motivação brasileira para abster-se de participar de forças multinacionais, estaria o país restrito apenas às missões de observação e afastado das operações de paz, por exemplo. As contradições brasileiras ou as brechas encontradas para atuar na Minustah podem encontrar ânimo na possibilidade de se firmar líder da região, à medida que o país questiona a “[...] ineficácia da cooperação norte-americana e canadense, presentes no país há mais de sessenta anos” (ROSA, 2007, p. 20).

Dessa forma, a inobservância da aplicação do princípio da não-indiferença pode ocasionar, conforme mencionado por Lima, a ingerência dos assuntos internos haitianos, ao passo que faz uso da justiça social para atingir outros fins. Deve-se ressaltar, todavia, que o Haiti consentiu com a operação de paz, mas sua instabilidade política, reflexo de 34 golpes de Estado diluídos em 210 anos de independência, e a extrema pobreza, que encontra raízes ainda durante a colonização francesa, tem transformando o país em campo permissivo à ingerência (VEREINTACH, 2008; SMARTH, 2010).

Findo o processo decisório para integrar a Minustah, o Brasil apresentaria novamente uma postura contraditória ao seu discurso, já atuando em campo 
haitiano. O apoio à realização de eleições no Haiti, um dos pilares da resolução que deu origem à Missão, ocorreu em 2006, quando o país se mobilizou para eleger aquele que ocuparia o cargo de presidente respaldado por eleições democráticas.

No entanto, apesar da declaração do governo brasileiro sobre o sucesso do processo eleitoral (FOLHA, 2006), a manobra realizada para anunciar a vitória de René Préval ao cargo de presidente apenas confirmou a ingerência brasileira no Haiti. Diante do resultado do primeiro turno, o caminho constitucional seria conduzir o processo eleitoral ao segundo turno, considerando que nenhum candidato alcançou mais de 50\% dos votos (SMARTH, 2010).

Face ao que poderia ocorrer, caso houvesse o segundo turno, a comissão eleitoral decidiu atribuir os votos em brancos proporcionalmente aos votos válidos atribuídos a cada candidato, no primeiro turno, atingindo dessa forma o objetivo de proclamar Préval o novo presidente haitiano. Como observa Rosa (2007, p. 17), após entrevista realizada em Porto Príncipe com o candidato derrotado Leslie Manigat sobre a manobra e o resultado das eleições:

Se analisarmos o ponto de vista daqueles que saíram vencidos das eleições de 2006, amargando a influência da política de relações exteriores brasileira de contagem de votos de uma maneira diferenciada com a finalidade instrumental de decretar a vitória de Préval, o Haiti ainda corre o sério risco de desestabilização civil.

Com efeito, ainda que o Brasil tenha apoiado a declaração antecipada de Préval, argumento pautado nos problemas que poderiam surgir em decorrência da realização do segundo turno, não justifica o desrespeito e a ingerência ao ordenamento jurídico interno haitiano. A prática democrática que permeia o discurso brasileiro, diante desse episódio, quanto à sua aplicabilidade, mostra-se relativa. E, por certo, escolhas como essa não refletem na construção sustentável da paz, porque o caminho percorrido para a persecução de tal fim demonstra-se incoerente. 


\section{Retórica da política ou política da retórica?}

O episódio que acentuou o desejo expresso do Brasil em disputar hegemonia regional por meio do Haiti foi o terremoto de 12 de janeiro de 2010. Por liderar militarmente a MINUSTAH, o Brasil entendeu que a ação rápida de envio de 12 mil soldados americanos à ilha ignorava seu comando militar, já que as forças militares norte-americanas bloquearam, por alguns dias, o aeroporto e o porto da capital haitiana. A atitude norte-americana foi duramente criticada por chefes de Estado da Aliança Bolivariana para as Américas, como Fidel Castro, Hugo Chávez e Evo Morales e por organizações de ajuda humanitária. De acordo com o antropólogo Federico Neiburg, em entrevista ao jornal O Globo,

Imediatamente depois do terremoto, a Minustah e as tropas brasileiras ficaram absolutamente paralisadas. As baixas brasileiras podem explicar em parte a demora em reagir. Mas isso explica muito pouco. A população esperou dias e dias que houvesse presença da ONU em Porto Príncipe, que é área de atuação do batalhão brasileiro, e do Brasil nas ruas. Isso não houve. Isso foi uma oportunidade perdida. (SANCHEZ, 2010).

Neiburg prossegue na constatação do descontrole à época do terremoto:

O que está acontecendo hoje [sic] é um escândalo, porque as forças estão totalmente descoordenadas, o problema humanitário está sendo tratado com critérios militares e isso não é um bom sinal para o futuro do país. (SANCHEZ, 2010).

A lógica de atuação do Brasil no Haiti, desde 2004, priorizou o contingente militar. Talvez por um entendimento exageradamente próprio, de caráter realista, de que problemas políticos são passíveis de resolução por meio da força armada, talvez para reproduzir o modelo de atuação norte-americana em diversas partes do mundo, como forma de disputar hegemonia regional ou talvez por aceitar a liderança militar de uma Missão controversa, aprovada e inúmeras vezes aditada pelo órgão das Nações Unidas mais identificado com os pressupostos realistas: o Conselho de Segurança, do qual o próprio Brasil anseia fazer parte como membro permanente (GUIMARÃES, 2008). 
Mesmo sem qualquer condição militar de intervir rapidamente no terremoto, as ações de longo prazo propostas pelo Brasil também não renderam nenhum resultado. Embora o atual Ministro das Relações Exteriores, Antônio Patriota, à época Secretário das Relações Exteriores do MRE, tenha assinado um Memorando de Entendimento com o governo haitiano em 25 de fevereiro de 2010, para implementar um modesto programa de intercâmbio de estudantes haitianos ao Brasil, posteriormente homologado pela CAPES pela Portaria No. 92, de 27 de abril de 2010, com a promessa da implantação do Programa intitulado Pró-Haiti, esta ação supostamente emergencial até o momento ainda não saiu do papel.

Soma-se a essa paralisia do serviço público brasileiro em dar respostas rápidas a esta catástrofe humanitária da qual o Brasil se apresenta retoricamente como principal fiador e interessado, a controvertida polêmica em criminalizar imigrantes ilegais haitianos em solo brasileiro (VARGAS, 2010), a exemplo do que já ocorreu em Mato Grosso do Sul e da grave situação humanitária vivida por imigrantes ilegais no Acre e na Amazônia, confinados em Brasileia, no interior do Acre, dentro de um Ginásio de Esportes (VIEIRA, 2011), também é outro ponto sensível em relação à disposição do Brasil em cooperar efetivamente com o Haiti ou de tentar construir uma política de viés não realista. Ademais, as dificuldades de obtenção de vistos de haitianos para a vinda ao Brasil, o rigor das exigências consulares e uma política de atendimento não diferenciada para um povo que, no discurso das autoridades brasileiras é “irmão", revela a falta de disposição do governo brasileiro em redirecionar sua política para o Haiti. (DISCURSO..., 2011b).

Ainda e a título de conclusão, o Congresso Nacional brasileiro também está sendo pressionado a legislar sobre o Haiti, a partir de casos concretos, não apenas para o envio de parlamentares em viagens curtas e bem protegidas a Porto Príncipe. Em face da possível permanência de uns poucos haitianos ao solo brasileiro, o Senado pretende aprovar uma "Comissão para averiguar a situação dos haitianos que cruzaram de forma clandestina a fronteira brasileira”, a pedido dos Senadores Jorge Viana e Aníbal Diniz, ambos do PT do Acre, os quais veem como alarmante a situação desses imigrantes em seu Estado. É preciso, pois aguardar o resultado do posicionamento do Congresso Nacional para delimitar melhor o controvertido posicionamento brasileiro a respeito do Haiti. 


\section{Conclusão}

As práticas políticas alternativas que têm surgido em contraposição à ordem mundial vigente são contributos importantes e imprescindíveis para o aprimoramento dos mecanismos e instrumentos utilizados para alcançar a paz. No caso brasileiro, a política de prestígio centrada em discursos voltados para a inclusão, o desenvolvimento, a proteção ao meio ambiente e a justiça social, no campo doméstico, e o multilateralismo, na esfera internacional, tem imprimido ao país reconhecimento perante a comunidade internacional.

A postura pacifista e humanista adotada pelo Brasil tem, portanto, se transformado em uma excelente estratégia para a sua inserção, ainda que frágil, na esfera internacional. No entanto, mesmo que a memória histórica brasileira confirme a tradição de usar a diplomacia e dispensar as armas, as contradições apresentadas frente à Minustah evidenciam a corrupção da política de prestígio. O Brasil, no anseio de se firmar líder e porta-voz dos países em desenvolvimento e de conseguir um assento permanente no CS, atropelou-se no seu próprio discurso, pautado nos princípios de não-ingerência e não-indiferença, e mostrou-se despreparado para atuar em situações-limite, como ocorreu no Haiti.

Neste último caso, considerando o contexto de operação de paz, se, como afirma Chandler (2006), comumente os atores internacionais estão focados no viés burocrático, administrativo e legal, por certo o discurso brasileiro apresenta-se como um contraponto por direcionar sua atuação aos componentes sociais e econômicos. Entretanto, ao deparar-se com a prática, o Brasil indubitavelmente mostra fragilidades de gestão e coordenação política bastante importantes. Nesse sentido, a bandeira humanista levantada pela política externa brasileira certamente imprime impactos positivos na comunidade internacional e nos fóruns multilaterais dos quais o Brasil participa. Contudo, as contradições apresentadas e o desnivelamento entre o que o discurso aponta e as práticas institucionais, quase sempre lentas ou desfavoráveis ao povo haitiano podem desacreditar o belíssimo discurso de justiça social das autoridades brasileiras. Consequentemente, projetos mais ambiciosos como um assento permanente no Conselho de Segurança e a liderança da América do Sul podem não se concretizar em decorrência das dúvidas que a política de prestígio que o Brasil engendra quando não se coordena adequadamente 
com a capacidade de ajuda humanitária que o Brasil poderia oferecer neste cenário desfavorável que o Haiti se encontra.

É notável que a presença do Brasil no Haiti tenha encontrado diversos questionamentos, que vão desde enfoques metodológicos equivocados, à visão realista impingida à Minustah, apesar de seu componente inovador de Direitos Humanos (CAVALLARO, 2005). As respostas das autoridades brasileiras a esta realidade e às críticas em face de sua atuação são evasivas e sem foco. $\mathrm{O}$ mais lamentável, no entanto, é o fato de o governo brasileiro ignorar a crise política vivida em 2010 quando da transição do atual Presidente René Préval. Na visão do ex-chanceler Celso Amorim, o Presidente Préval [deve ser parabenizado] pelos esforços para garantir que as eleições de novembro aconteçam de acordo com a Constituição haitiana (BRASIL, 2010). Infelizmente, por apoiar um governo contraditório e sem legitimidade, o Brasil não divulgou nenhuma nota de protesto ao fato de Préval ter impetrado ações explícitas de prorrogar seu mandato por tempo indeterminado. Não fosse a forte pressão popular haitiana (HAITI NEWS, 2010), Préval não teria voltado atrás nesta lamentável decisão.

Por fim, a posição do governo brasileiro é favorável, sem nenhum motivo justificado, pela continuidade do mandato da Minustah, sem qualquer alteração, nem mesmo uma possível mudança no nome: de Missão de Estabilização Civil para Missão de Reconstrução, por exemplo. Ademais, advoga que o país que ocupa a $11^{\text {a }}$ posição no ranking de falência do Estado (INDEX DOS ESTADOS FALIDOS, 2010) está a caminho da consolidação da democracia. Nas palavras de Amorim:

É uma questão de bom senso que apenas após a segunda eleição sucessiva pode-se considerar a democracia consolidada. Na nossa opinião, o nível de engajamento da MINUSTAH deve permanecer inalterado até o mandato do próximo presidente. (DISCURSO..., 2011a). 


\section{Brazil and the non-indifference to haitian crisis: solidarity or the rhetoric of discourse?}

\section{Abstract}

After the fall of Berlin wall, Brazil has centered efforts to develop a policy of prestige to interpose the neoliberal from the North. Notwithstanding, the country has sought established itself as a leader in its region, and also has placed in its external agenda an approximation to Arabian countries, as well as with Latin-American and African ones, underpinned on dialogue and cooperation. Moreover, has pleaded incisively for the reform on the ONU Security Council, arguing that this space should correspond to a new order which implies a more active participation of developing countries, not exempting itself to eliminate the imbalances between the industrialized and the developing countries. This way, Brazil projects itself as a moderator on the north-south relations, seeking to affirm the sovereignty of the nations. In April 2004, accepted the mission to lead the United Nations Stabilization Mission in Haiti (Minustah), an opportunity that allowed the country to apply its pacific and mediation policy. On this sense, adopting the Minustah as a study case, the present article has as its objective to analyze if the Brazilian performance, face this peace operation, correspond with its non-interfering speech, and then, bring questions that might course through this performance.

Keywords: Brazil. Haiti. MINUSTAH. United Nations Security Council.

\section{Referências}

ALMEIDA, Paulo Roberto de. Uma nova arquitetura diplomática? interpretações divergentes sobre a política externa do governo Lula (2003-2006). Revista Brasileira de Política Internacional, [S.1], v. 1, n. 49, p. 95-116, 2006.

BARBOSA, Alexandre de Freitas et al. Brazil in Africa: another emerging country in the continent? Politikon, [S.l], v. 1, n. 36, p. 59-86, 2009.

BRASIL. Celso Amorim. Discurso do Ministro das Relações Exteriores, Celso Luiz Nunes Amorim, na abertura da XXXV Assembleia Geral da OEA, em Fort Lauderdale (USA) em 05 de junho de 2005. Disponível em: <http://www.oas.org/ 
speeches/speech.asp?sCodigo=05-0114> Acesso em: 10 de nov. 2010.

BRASIL. Constituição (1988). Constituição da República Federativa do Brasil. Brasília: Senado Federal, 2009.

BRASIL. Luiz Inácio Lula da Silva. Discurso do Presidente da República Federativa do Brasil na cerimônia de posse, em $1^{\circ}$ de janeiro de 2003. Disponível em: <http:// www.planalto.gov.br/publi_04/COLECAO/DISPRES.pdf> Acesso em: 8 nov. 2010.

BRASIL. Ministério da Saúde. Entrevista com o Ministro das relações exteriores Celso Amorim. Cooperação Saúde: boletim da atuação internacional brasileira em saúde. Abril de 2010a. Disponível em:<http://portal.saude.gov.br/portal/arquivos/ pdf/boletim_aisa_final.pdf $>$ Acesso em: 10 nov. 2010.

BRASIL. Palácio do Planalto. Entrevista do Presidente Luiz Inácio Lula da Silva à rede de TV Al Jaziera. Disponível em:<http:// blog.planalto.gov.br/entrevistaa-tv-al-jazeera-tento-na-presidencia-retratar-um-pouco-do-que-vivi-na-minhavida/>. Acesso em: 15 nov. 2010.

BREWER, John, D. Peace Process: a sociological approach. Cambridge: Polity Press, 2010.

BRIGAGÃO, Clóvis; PROENÇA, Domício (Org.). O Brasil e os novos conflitos internacionais. Rio de Janeiro: Gramma, 2006.

CASIMIR, Jean. Haiti et sés eleites - l'interminable dialogue de sourdes. Haiti: Úniversité d'État d'Haiti, 2009.

CAVAlLARO, James. Mantendo a paz no Haiti? uma avaliação da missão de estabilização das Nações Unidas no Haiti usando o cumprimento de seu mandato como parâmetro de sucesso. Cambridge, MA: Harvard Law Student Advocates for Human Rights; Rio de Janeiro, São Paulo: Centro de Justiça Global, mar. 2005.

CENTRO DE MÍDIA INDEPENDENTE. Manifesto da campanha: não ao envio de tropas ao Haiti. Disponível em: <http:// www.midiaindependente.org /pt/ blue/2004/04/277171.shtml>. Acesso em: 8 dez. 2010.

CHANDLER, David. Empire in denial: the politics of state-building. London: Pluto, 2006.

CORRÊA, Luís Felipe de Seixas. O Brasil nas Nações Unidas (1946-2006). Brasília: Alexandre de Gusmão, 2007. 
DISCURSO do Ministro Celso Amorim na Reunião Extraordinária da Comissão Interina de Reconstrução do Haiti. Disponível em: <http://www.itamaraty.gov. br/ sala-de-imprensa/notas-a-imprensa/discurso-do-ministro-celso-amorim-nareuniao-extraordinaria-da-comissao-interina-de-reconstrucao-do-haiti-2013nova-york-20-de-setembro-de-2010>. Acesso em: fev 2011a.

DISCURSO do Presidente da República, Luiz Inácio Lula da Silva, na cerimônia de embarque das tropas militares para missão de paz no Haiti. Disponível em: http:// www.itamaraty.gov.br/sala-de-imprensa/discursos-artigos-entrevistas-e-outrascomunicacoes/presidente-da-republica-federativa-do-brasil/560382073724discurso-do-presidente-da-republica-luiz-inacio. Acesso em: fev. $2011 \mathrm{~b}$.

ESTADÃO. Lula e Ahmadinejad reclamam nova ordem mundial. Disponível em: <http://www.estadao.com.br/noticias/internacional,lula-e-ahmadinejadreclamam-nova-ordem-mundial,552559,0.htm>. Acesso em: 9 dez. 2010.

FOLHA. Brasil comemora passo fundamental dado pelo Haiti. Disponível em: <http://www1.folha.uol.com.br/folha/bbc/ult272u50983.shtml>. Acesso em: 15 nov. 2010.

GUIMARÃES, Samuel Pinheiro. In: ENCONTRO NACIONAL DE ESTUDOS ESTRATÉGICOS, 4., 2008, Anais... Brasília: Presidência da República, 2008.

HAITI News. Haiti: opposition protests “emergency law”. Disponível em: <http:// www.ayitinou.com/article-posts/29-haitian-articles/2109-haiti-oppositionprotests-qemergency-lawq.html>. Acesso em: maio 2010.

HERZ, Mônica. O Brasil e a Reforma da ONU. Lua Nova, [S.1], v. 99, n. 46, p. 77-98, 1999. doi: 10.1590/S0102-64451999000100004.

HURRELL, Andrew. Brazil and the new global order . Current History, [S.1], v. 724, n. 109 , p. $60-66,2010$.

INDEX DOS ESTADOS FALIDOS. Fund for Peace. Disponível em: <http://www. fundforpeace.org/web/index.php?option=com_content\&task=view\&id=452\&Ite mid=900> . Acesso em: fev. 2011.

LAFER, Celso. Brasil: dilemas e desafios da política externa. São Paulo, Revista Estudos Avançados, v. 14, n. 38, p. 260-267, jan./abr., 2000. doi: 10.1590/S010340142000000100014. 
LESSA, Carlos Antônio et al Política externa planejada: os planos plurianuais e a ação internacional do Brasil, de Cardoso a Lula (1995-2008) Revista Brasileira de Política Internacional, [S.1], v. 1, n. 52, p. 89-109, 2009.

LIMA, Maria Regina Soares de. Autonomia, não indiferença e pragmatismo: vetores conceituais da política exterior. Revista Brasileira de Comércio Exterior, [S.1], n. 83, p. 16-20, abr.-jun. 2005.

LIMA, Maria Regina Soares de; HISRT, Mônica. Brazil as an intermediate state and regional Power: action, choice and responsibilities. International Affairs, [S.l], v. 1, n. 82, p. 21-40, 2006.

MIYAMOTO, Shiguenoli. O Brasil e as negociações multilaterais. Revista Brasileira de Política Internacional. Brasília, UnB, v. 1, n. 43, p. 119-137, 2000.

MORGENTHAU, Has J. Politics among nations: the struggle for power and peace. New York: Mc Grill, 1993.

NYE, Joseph S. Cooperação e conflito nas relações internacionais. São Paulo: Gente, 2009.

PARIS, Roland. At war's end. Building peace after civil conflicts. Cambridge: Cambridge University, 2004.

PAULA, Bruna Vieira. O Brasil e os direitos humanos: do conservadorismo à valorização. Meridiano, [S.1], v. 110, n. 47, p. 28-30, 2009.

PECEQUILO, Cristina Soreanu. A política externa do Brasil no século XXI: os eixos combinados de cooperação horizontal e vertical. Revista Brasileira de Política Internacional, [S.1], v. 2, n. 51, p. 136-153, 2008.

RICHMOND, Oliver P. Peace in international relations. London: Routledge, 2008.

ROSA, Renata de Melo. Eleições de 2006 no Haiti: um debate sobre legitimidade. In: SANTANDER, Carlos Ugo; PENTEADO, Nelson Freire. Os processos eleitorais na América Latina. Brasília: LGE, 2008.

ROSA, Renata de Melo. Relatório final de pesquisa de pós-doutorado intitulada diplomacia responsável: a intervenção do Brasil no Haiti. [Brasília], 2007.

SADENBERG, Ronaldo Mota. Brasil, política multilateral e Nações Unidas. Estudos Avançados, [S.1], v. 53, n. 19, p. 347-367, 2005. 
SANCHEZ, Giovana. Com 12 vezes mais soldados que o Brasil, EUA usam tática militar no Haiti. G1, Rio de Janeiro, 23 jan. 2010. Disponível em: <http:/g1.globo.com/Noticias/ Mundo/0,,MUL1459182-5602,00-COM+VEZES+MAIS+SOLDADOS+QUE+O+ BRASIL+EUA+USAM+TATICA+MILITAR+NO+HAITI.html>. Acesso em: fev. 2011.

SARAIVA, Miriam Gomes. As estratégias de cooperação sul-sul nos marcos da política externa brasileira de 1993 a 2007. Revista Brasileira de Política Internacional, [S.1], v. 2, n. 50, p. 42-59, 2007.

SLATER, David. Geopolitics and the post-colonial: rethinking north-south relations. Oxford: Blackwell, 2004.

SMARTH, Rosny. Crise, movimento popular, intervenção estrangeira e a presença da América Latina no Haiti. Revista Universitas: Relações Internacionais, Brasília, v. 8, n. 2, p. 177-188, jul./dez. 2010.

SPEKTOR, Matias. Ideas of regional activism: the transformation of Brazilian readings of region. Revista Brasileira de Relações Internacionais, v. 53, n. 1, p. 2544, 2010.

UZIEL, Eduardo. O Conselho de Segurança, as operações de manutenção da paz e a inserção do Brasil no mecanismo de segurança coletiva das Nações Unidas. Brasília: Fundação Alexandre de Gusmão, 2010.

VARGAS, Rodrigo. Haitianos ilegais flagrados em MS ficam em abrigos e são notificados a deixar o país. Folha online, São Paulo, 18 mar. 2010. Disponível em: $<$ http://www1.folha.uol.com.br/folha/cotidiano/ult95u 708992.shtml>. Acesso em: fev. 2011.

VERENHITACH, Gabriela Daou. A Minustah e a politica externa brasileira: motivações e consequências. . Santa Maria: Universidade Federal de Santa Maria, Centro de Ciências Sociais e Humanas, Pós-Graduação em Integração Latino-Americana, 2008. Disponível em: <http://cascavel.cpd. ufsm.br /tede/tde_arquivos/27/TDE-2008-12-18T170503Z-1830/Publico / GABRIELADAOUVERENHITACH.pdf> Acesso em: 14 nov. 2010.

VIEIRA, Sérgio. Senado pode avaliar situação de haitianos no Brasil. Rádio Senado, Brasília, 03 mar. 2011. Disponível em: <http://www.senado.gov.br/noticias/ Radio/programaConteudoPadrao.asp?COD_TIPO_PROGRAMA=4\&COD_ $\mathrm{AUDIO}=35970>$. Acesso em: fev. 2011. 
VIGEVANI, Tullo et al. O papel da integração regional para o Brasil: universalismo, soberania e percepção das elites. Revista Brasileira de Política Internacional, [S.l], v. 51, n. 1, p. 5-27, 2008.

WOODWARD, Susan. Estados falidos: o peso das palavras, Engeux Internationaus, n.11, jan./mar., 2006. 


\section{Para publicar na revista Universitas}

Relações Internacionais, entre no endereço eletrônico www.publicacoesacademicas.uniceub.br. Observe as normas de publicação, facilitando e agilizando o trabalho de edição. 